\title{
A comunicação de Más Notícias na UTI: Perspectiva dos Médicos
}

\author{
Daniela Trevisan Monteiro ${ }^{1}$ \\ Universidade Federal do Rio Grande do Sul \\ Alberto Manuel Quintana \\ Universidade Federal de Santa Maria
}

\begin{abstract}
RESUMO - Este estudo objetivou compreender o processo de comunicação de más notícias no contexto da uma Unidade de Tratamento Intensivo para adultos, na perspectiva dos médicos. Configurou-se como uma pesquisa qualitativa, de caráter exploratório e descritivo. Os dados foram coletados a partir de entrevistas semiestruturadas e observação registrada em diário de campo. Participaram 12 médicos de um hospital-escola do interior do Rio Grande do Sul. A análise foi realizada por meio da análise de conteúdo. Destacam-se dificuldades dos médicos em comunicar más notícias, bem como o uso de mecanismos de defesa para realizar essa tarefa. Considera-se necessário resgatar a importância da reflexão sobre a relação médico-familiar como prática diária tão importante para a medicina.
\end{abstract}

Palavras-chave: comunicação, psicologia médica, relações profissional-família

\section{The Communication of Bad News in ICU: Perspective of Doctors}

\begin{abstract}
This study aimed to understand the process of the bad news communication in the context of the Intensive Care Unit for adults, from the perspective of the doctors. It was configured as a qualitative, exploratory and descriptive research. Data were collected through semi-structured interviews and observation recorded in daily field. Participated 12 doctors in a teaching hospital of Rio Grande do Sul. The analysis was performed through the content analysis. The results highlight the difficulties of the doctors to communicate bad news, as well as the use of defense mechanisms to accomplish this task. It is necessary to recover the importance of reflection on the doctor-family relationship as daily practice as important to the medicine.
\end{abstract}

Keywords: communication, medical psychology, professional-family relations

A saúde passa por grandes desafios nas questões relativas à qualidade de vida. Por um lado há um real avanço científicotecnológico e, por outro, se reconhece o importante papel de uma medicina humanizada. Nesse cenário, as tecnologias diferenciadas atraem a atenção e, por vezes, até lateralizam as ações relativas à humanização, criando uma interpretação errônea de que a solução para uma melhora da qualidade de vida está nos sofisticados aparelhos e nos diferenciados recursos terapêuticos (Lottenberg, 2010). Logo, o modelo médico prioriza os sinais e sintomas, tornando secundário o cuidado aos aspectos psíquicos e/ou emocionais dos envolvidos. Mas, para além da tecnologia, há de se considerar que toda relação estabelecida entre o médico e o paciente/ familiar é sustentada por encontros, conversas e afetos e atravessada por conflitos que abarcam os processos de subjetivação (Rodrigues, Moraes, Betoschi, \& Amaral, 2015). Entre os fatores que contribuem para o prejuízo na relação do médico com o paciente/familiar encontram-se os problemas de comunicação enfrentados pelo profissional (Castro \& Barreto, 2015).

A comunicação faz parte do cotidiano dos profissionais de saúde e implica na interação entre eles, paciente e familiares (Borges, Freitas, \& Gurgel, 2012). É uma ferramenta importante na relação médico paciente/familiar

1 Endereço para correspondência: Universidade Federal de Santa Maria, Avenida Roraima 1000, CCSH, Prédio 74B, Sala 3212a, Camobi, Santa Maria, RS, Brasil. CEP: 97.105-900. E-mail: daniela.trevisan. monteiro@gmail.com e deve ser aperfeiçoada para diminuir o impacto emocional e proporcionar melhor assimilação da nova realidade. Saber informações sobre diagnóstico e prognóstico permite que pacientes e família vivenciem o momento de forma menos dolorosa (Rodriguez, 2014). A comunicação de más notícias é aquela que causa sensações desagradáveis em um de seus agentes, principalmente aquelas associadas a diagnosticar e prognosticar enfermidades, sendo essa uma constante no cotidiano dos profissionais de saúde (Borges et al., 2012).

Para que ocorra a comunicação entre médico e paciente/ familiar é primordial considerar a palavra interação, pois a comunicação envolve a transmissão de informação contínua de uma pessoa para a outra, sendo então compartilhada por ambas, de modo que o destinatário a receba e a compreenda. Se a informação foi apenas transmitida, porém, não recebida, não foi efetivamente comunicada, sendo necessário alinhar o transmissor e o receptor entre os participantes do processo (Moritz et al., 2008).

Na hospitalização, a família experimenta desafios, não apenas relacionados às exigências do papel do cuidar, mas igualmente enfrentam a dor e o luto em relação à possível morte do ente querido (Rodriguez, 2014). Para o familiar, a comunicação de más notícias é um momento de angústia, sua capacidade de entendimento está limitada. Assim como o paciente, ele pode possuir dificuldades em se expressar por meio das palavras, pois está exposto a angústias e fragilidades, que inibem formas mais complexas de comunicação. Nesse ínterim, há diminuição da capacidade 
de assimilação das explicações e orientações passadas pelo médico. Já para o médico, sua formação conspira contra uma comunicação acessível, o que o leva ao uso de jargões que pacientes e familiares não conseguem entender. $\mathrm{O}$ maior desafio, então, é transformar verdades complexas em informações compreensíveis para pessoas angustiadas e com muitas incertezas (Lucchese \& Ledur, 2008).

Nesse sentido, para que os canais de comunicação estejam abertos e família e paciente possam se expressar é preciso que a equipe médica aperfeiçoe a comunicação de más noticias e se encontre preparada para suportar as demandas que emergem nessas situações, respeitando as necessidades dos pacientes e da família e os amparando em uma possível despedida de seu ente querido (Rodriguez, 2014). A comunicação poderá ser tanto terapêutica, realizada a fim de beneficiar a família e a ajudar na vivência de internação; quanto nociva, podendo comprometer sua saúde física e mental e proporcionar momentos traumáticos (Santos, Oliveira, Veronez, \& Nogueira, 2015).

Alguns médicos reconhecem a dificuldade que enfrentam em comunicar, pois estabelecer uma comunicação proporciona diálogos e vínculos com pacientes e familiares. $\mathrm{Na}$ comunicação de más notícias vários afetos estão presentes, afligindo os profissionais, pacientes e familiares (Almeida \& Santos, 2013). Logo, a questão principal para os profissionais de saúde não é saber informar os pacientes/familiares, mas sim saber o quanto, como e quando informar, principalmente quando a informação se refere a más notícias, como os diagnósticos de doenças graves (Pereira, 2005). Portanto, no tocante à comunicação, as más notícias constituem tema de suma importância na relação médico paciente/familiar.

Comunicar más notícias é considerada uma tarefa estressante para os médicos, e muitos evitam sua transmissão ou a realizam de maneira inadequada (Lino, Augusto, Oliveira, Feitosa \& Caprara, 2011). Por vezes, os profissionais encaram a situação da comunicação de más noticias como um fracasso. Nesse sentido, os processos de comunicação podem vir a ser esvaziados de conteúdo, como consequência do uso inconsciente de mecanismos de fuga, levando ao uso de eufemismos, para não deixar a sensação de falta de transparência e omissão (Pereira, 2005). Assim, a comunicação de más notícias, tanto para o paciente/ familiar quanto para o médico, é considerada desagradável e desconfortável. Trata-se de um momento difícil que envolve emoções e reações experienciadas pelo paciente/familiar, enquanto fonte adicional de estresse, e, ainda, o fato de o médico ter de lidar com suas próprias emoções, receios e o enfrentamento de sua finitude (Lino et al., 2011).

Apesar de as Diretrizes Curriculares Nacionais para a Graduação em Medicina enfatizarem a relevância da comunicação como uma competência a ser bem desenvolvida pelos graduandos, o texto é superficial no que se refere à importância da habilidade na relação médico-paciente/ familiar. Além disso, poucas universidades valorizam o ensino da comunicação verbal e não-verbal em seus currículos (Rossi-Barbosa, Lima, Queiroz, Fróes, \& Caldeira, 2010). Esse assunto também é assinalado por Lino et al. (2011) que apontaram que, embora a comunicação de más notícias seja objeto de estudo em diversos cursos de medicina em nível internacional, o tema ainda é pouco abordado por professores e estudantes no contexto brasileiro. Assim, observa-se cada vez mais uma crescente preocupação mundial com a formação dos profissionais da saúde, na medida em que se passa a deslocar o eixo do "o que fazer" (conhecimento técnico-científico), para "como fazer" abordando, assim, as práticas de comunicação profissional-paciente/familiar.

Destaca-se que os processos de comunicação são fundamentais no estabelecimento da conduta, principalmente porque o doente/familiar, ao chegar à frente do médico, pode se encontrar em um estado emocional regressivo. Portanto, tanto a confiança no médico quanto o sucesso da terapêutica dependerão de uma comunicação adequada entre o profissional de saúde e o paciente/familiar (RossiBarbosa et al., 2010). Porém, se a doença evolui e o médico não encontra mais amparo nos recursos tecnológicos, a falta de preparo dos profissionais para a comunicação e para o suporte emocional aos pacientes e familiares fica evidente, resultando em silenciamentos, falsas promessas de cura ou comunicações abruptas de prognósticos adversos, com sérios prejuízos à relação terapêutica (Penello \& Magalhães, 2010).

Os trabalhos sobre a comunicação de más noticias geralmente abordam a comunicação ao paciente. Contudo, nas Unidades de Tratamento Intensivo (UTIs) podemos considerar que essa comunicação é feita quase que exclusivamente com os familiares dos pacientes internados. Assim sendo, considera-se que para poder melhorar esse processo de comunicação das más notícias tornase imprescindível conhecer como os médicos de UTIs, encarregados de realizar essa tarefa, dão sentido a esse processo e qual é o significado que para eles tem a ação de comunicar más notícias aos familiares dos pacientes internados.

Desse modo, a pesquisa norteia-se pela seguinte pergunta: Como ocorrem as comunicações de más notícias e que implicações essa tarefa possui na conduta médica? O objetivo principal é compreender o processo de comunicação de más notícias no contexto de uma UTI para adultos, na perspectiva dos médicos.

\section{Método}

\section{Desenho do Estudo}

$\mathrm{O}$ estudo proposto caracteriza-se como qualitativo (Minayo, 2010), de caráter exploratório e descritivo (Gil, 2010). O molde qualitativo é o que melhor se encaixa na análise das vivências subjetivas que acontecem com os participantes durante o processo de comunicação de más notícias.

\section{Participantes}

Participaram deste estudo 12 médicos que exercem atividade em UTI de um hospital-escola do interior do Rio Grande do Sul, sendo oito do sexo masculino e quatro do sexo feminino, com idades no intervalo de 26 a 57 anos. 
Foi incluída nas entrevistas a totalidade dos médicos atuantes na UTI onde se realizou a pesquisa. Todos estavam em contato com os familiares e/ou pacientes para comunicar uma notícia na evolução do quadro geral apresentado pelo paciente, indiferente dessa comunicação ser específica de má notícia.

\section{Técnicas e Procedimentos de Coleta de Dados}

Os dados foram coletados por meio de entrevistas semiestruturadas e observação não participante registrada em diário de campo. A entrevista é uma forma de comunicação verbal privilegiada de interação (Minayo, 2010). Já a técnica da observação permite o entendimento do comportamento global do sujeito entrevistado no decorrer da relação estabelecida. A partir dos achados anotados para a posterior análise, é dada importância ao estilo e às alterações psicológicas e da fala, como por exemplo: interposição de momentos de silêncio, fala embargada, palavras pronunciadamente vaciladas, colocações com inibição e desinibição, manifestação de atos falhos. Ainda, deve-se considerar os elementos de apresentação pessoal, aspectos do comportamento global e a comunicação não-verbal, como: mudanças de postura física, gesticulações, mudanças afetivas no timbre e volume da voz, entre outros (Turato, 2013).

Os participantes foram abordados no próprio local de trabalho por mediação do chefe da unidade. Inicialmente foram esclarecidos sobre a temática e os objetivos do trabalho, riscos, benefícios e sigilo. Após, foi realizado o convite para a participação na pesquisa, posteriormente às explicações sobre a pesquisa, e quando aceito o convite, solicitou-se consentimento verbal e escrito, sendo que o Termo de Consentimento Livre e Esclarecido (TCLE) foi assinado por todos os participantes. Foi observado tanto o ambiente da UTI quanto o momento da comunicação entre médico e familiares. Para possibilitar a observação no momento da comunicação entre médico e familiares, estes igualmente receberam as explicações sobre a pesquisa, e quando aceita a participação, assinaram o TCLE.

As observações na UTI foram realizadas concomitantes às entrevistas e aconteceram por um período de 45 dias. Esse período foi necessário para a ambientação do pesquisador no local da coleta de dados, bem como por se considerar a importância do pesquisador tornar-se uma figura conhecida entre a equipe de saúde e, principalmente, entre os familiares que se encontravam em um momento de fragilidade. As observações aconteceram com base em um roteiro explicitado a seguir:

a) Observação na Unidade de Tratamento Intensivo: Interação entre os membros da equipe de saúde; Tratamento aos pacientes; Referências às doenças; Comunicação entre os membros da equipe de saúde; Round da equipe de saúde.

b) Observação do momento da comunicação na relação médico-familiar: Processo de comunicação; Comportamentos subjetivos dos médicos; Comportamentos subjetivos dos pacientes e/ou familiares; Reações dos pacientes e/ou familiares frente à notícia;
No momento específico da comunicação entre médicos e familiares foram realizados 14 dias de observações; totalizando 121 comunicações observadas entre médicos e familiares. Em cada dia de comunicação ocorriam, aproximadamente, nove comunicações, considerando os familiares dos nove leitos da UTI. Houve dias em que não havia familiar presente, por isso o número de comunicações é menor que a mera multiplicação dos dias com o número de leitos.

Quanto à entrevista, esta foi realizada em uma sala da unidade já previamente disponibilizada para a pesquisa. Os eixos norteadores das entrevistas foram: Entrada/ingresso na UTI; Característica da UTI; O paciente da UTI; O ingresso do paciente na UTI; Relação da equipe com a família, do paciente com a família e entre a própria equipe; Comunicação do diagnóstico ao paciente e/ou familiar; Comunicação da evolução do quadro do paciente; Lembrança de uma comunicação que avalia como positiva; Lembrança de uma comunicação que avalia como negativa; Impressões sobre as reações dos receptores das más notícias; Exemplo de um caso clínico que teve desfecho desfavorável e outro com desfecho favorável; Futuro profissional; Aprendizagem da comunicação.

O momento para a realização da entrevista foi escolhido pelos participantes, ocorrendo de forma individual e sigilosa. As entrevistas foram gravadas e posteriormente transcritas.

\section{Procedimentos de Análise dos Dados}

As entrevistas foram analisas a partir da análise de conteúdo proposta por Bardin (2008) e Turato (2013), pois esse tipo de análise trata das mensagens (comunicação), ou seja, as codifica (Bardin, 2008), explicitando o sentido contido em um documento com a finalidade de oferecer um significado por meio de palavras pré-escolhidas, frequência de repetição de termos, aparato e andamento do discurso (Turato, 2013). A partir dessa análise, primeiramente, foi realizada uma leitura flutuante, que consiste em uma préanálise, enquanto forma de assimilação de todo o material coletado de modo a permitir a categorização dos dados que foi feita a partir dos critérios de repetição e relevância (Turato, 2013).

\section{Considerações e Aspectos Éticos}

Foram mantidas todas as recomendações éticas propostas na resolução 466/12 do Conselho Nacional de Saúde (Brasil, 2012), que prescreve a ética na pesquisa com seres humanos. Para manter o anonimato dos participantes, os nomes foram trocados pela letra $\mathrm{M}$, seguida sistematicamente do número da entrevista, assim apresentou-se como: M1, M2, M3, M4 ..., sucessivamente. A pesquisa foi aprovada pelo Comitê de Ética em Pesquisa da instituição onde a pesquisa foi realizada, sob o número do Certificado de Apresentação para Apreciação Ética (CAAE): 0367.0.243.000-11. 


\section{Resultados e Discussão}

Por meio da análise dos dados procedentes da coleta de dados, surgiram determinadas categorias que exemplificam o processo de comunicação de más notícias na perspectiva dos médicos.

\section{A Comunicação de Más Notícias: Aprendizagem, Habilidade ou Estilo?}

Esta categoria versa sobre a maneira como o médico comunica as más notícias. Muitos médicos relataram sua dificuldade em comunicá-las. Frente a esse fato, é importante ressaltar que, durante o convite aos médicos para a participação na pesquisa, a reação foi de que seria necessária uma mudança na comunicação de más notícias. Da mesma forma, alguns médicos verbalizaram suas dificuldades logo no primeiro contato, ressaltando que não sabiam dar más notícias.

Principalmente comigo, eu não sei dar más notícias. (M4)

Duvidamos da capacidade dele em dar más noticias. (M9)

Cada médico, seja a partir de sua experiência profissional, da observação de outros colegas de trabalho ou aprendizado durante sua formação, busca, em concordância com seu estilo, uma forma de comunicar más notícias. Assim, a partir da análise das entrevistas, foi possível perceber diferentes formas de comunicá-las, baseadas em experiências pessoais e no senso comum, já que não houve, durante a formação dos médicos entrevistados, um treinamento ou um preparo para realizar essa ação. Embora a comunicação de más notícias seja objeto de estudo em diversos cursos de medicina a nível internacional, o tema ainda é pouco abordado por professores e estudantes no contexto brasileiro (Lino et al. 2011). Corroborando com esse pensamento, os médicos entrevistados foram categóricos na defesa do discurso da falta de ensinamento durante a formação, como demonstram as falas:

Nós aprendemos a dar notícias sozinhos. Nós não estudamos para dar más notícias, nós não somos treinados para dar más notícias. Então, isto é uma capacidade, assim, que a gente vai adquirindo dentro do curso de medicina, na formação médica, individualmente, e, todo o mundo tem esta dificuldade. (M2)

A primeira a gente observa, a segunda a gente faz e a terceira a gente ensina. (M3)

Pode-se inferir, a partir das falas, que a comunicação de más notícias não é vista como uma ação técnica. Além disso, fica explícito que esse aprendizado dá-se, geralmente, por meio da prática e pela observação dos docentes. Em relação ao processo de aprendizagem, Fornaziero, Gordan e Garanhani (2011) realizaram uma pesquisa com 16 estudantes do sexto ano de medicina da Universidade Estadual de Londrina, com o intuito de compreender o processo de ensino e aprendizagem do raciocínio clínico desenvolvido por estes. Nas respostas às entrevistas, os acadêmicos apontaram o docente como modelo de conhecimento. Entre as diversas formas de aprender, seja por repetição, leitura ou estudos individuais, o professor foi decididamente destacado como modelo a ser adotado pelo estudante, independentemente do período do curso. Dessa forma, a eficácia do professor é uma característica fundamental ao trabalho docente, considerando-se que o acadêmico o observa como modelo profissional. O médico busca, então, maneiras de realizar a comunicação, determinando a sua forma de comunicar, como se observa no relato:

Baseei-me muito, também, no que eu vejo na TV, porque é assim, na imagem disto, porque, para o leigo, qual é a imagem que ele tem da má notícia, é a imagem que ele vê todo o dia. E onde é que ele vê todo dia esta imagem? É na televisão, é no Jornal Nacional, [...], é no cinema, na TV, na hora em que vão falar com o médico, é na novela, na hora em que alguém se acidenta e que tá esperando o médico para falar. Então são estes termos que a população está acostumada a ouvir, é esta postura que a população está acostumada a ver, e ela vai esperar que tu haja desta maneira também. (M4)

Percebe-se nessa fala que o médico buscou um aprendizado mais voltado ao senso comum como forma de fazer-se entendido por parte dos pacientes e/ou familiares. Nessa perspectiva, em pesquisa realizada sobre o conhecimento e a utilização de estratégias de comunicação, evidenciou-se carência de habilidades de comunicação dos profissionais da saúde para oferecer apoio emocional. A superficialidade do conhecimento sobre estratégias de comunicação fica clara quando se avaliam informações complementares. Isto porque surge grande número de citações de expressões subjetivas nas respostas, tais como: solidariedade, compaixão, apoio, atenção, carinho, entre outras. Essas são descrições ou denominações de sentimentos e não de estratégias de ações concretas na atenção aos pacientes, expondo a dificuldade dos profissionais em diferenciá-las (Araújo \& Silva, 2012). Em contrapartida, a habilidade de comunicação é imprescindível para a construção de uma relação. Diante disso, essa relação passa a ser construída por meio do espaço da comunicação, sendo possível realizar negociações, discussões, entre outras ações (Borges \& D'Oliveira, 2011). Outros entrevistados relataram:

Dar má notícia. Olha, isto é intuitivo. A gente tem a formação médica geral e como o médico dá a má notícia para os pacientes pelos quais é responsável. (M5)

Mas, nunca um contato assim, a gente falando e alguém junto.

E nunca ninguém falou até onde eu posso me envolver até onde não (...) É, vendo os outros, também, mas, nunca ninguém me ensinou. (M6)

Aqui podemos observar dois aspectos. O primeiro é o esforço que o médico realiza para poder obter ferramentas para melhorar sua comunicação com o familiar. Na falta de uma aprendizagem na graduação, o mesmo lança mão da televisão, da observação dos seus professores ou, por vezes, por meio de cursos de formação, como também relatado, conseguindo estabelecer para si uma técnica que mantém na comunicação. Destarte, essa técnica pode ser considerada vinda a partir do bom senso do médico ou da academia, o que não proporcionaria uma padronização na comunicação, e sim estilos pessoais. A partir do seu estilo, o médico encontra sua melhor maneira de realizar a comunicação. Esse estilo pessoal inclui formas de se proteger frente a essa tarefa considerada tão difícil, como se observa: 
Mas, na UTI, o que a gente aprende, não por regra, nem por livro, tu tem que deixar para a família, o paciente um pouquinho pior do que ele está. Porque, se ele evoluir, de uma hora para a outra, ficar mal ... a família tem que estar preparada. [...]. O paciente está estável, dentro de sua instabilidade, né. Mas, as doenças são graves, então, ... a gente sempre tenta, ... eu, pelo menos, aprendi vendo isto e me espelhando lá no pronto socorro. [...]. É a velha história, é uma frase horrivel, mas, é a velha história, quando tu põe um gato no telhado em um dia de chuva, com uma casca de banana na frente. Quase, praticamente, ... praticamente mata para a família, para a familia ficar preparada e conseguir, se acontecer a coisa, que a gente não gosta, se o paciente evoluir mal, ... é uma defesa, né. A família está preparada. (M6)

Agravar a situação do paciente durante a comunicação, pode preparar os familiares para um possível óbito, possibilitando que reajam de forma mais branda se isso realmente acontecer. Igualmente, pode proteger o médico, que não se sente preparado, contra uma explosão emocional por parte dos familiares. Nas falas de outros entrevistados observou-se, igualmente, que em torno da comunicação de más notícias há sempre a utilização de estratégias, como forma de proteger o médico dessas situações estressantes:

A grande maioria das vezes, eu começo a falar sempre no tempo verbal passado. [...] Dai eu iniciei a falar, no tempo verbal no passado, e eles ficaram prestando atenção no que eu falava, prestando atenção no que eu falava, dai quando eu não tinha mais o que falar, dai eu disse, infelizmente, ele faleceu. Daí eles começaram a chorar, dai eles não acreditam, meu pai, não sei o que. Mas ali, a minha impressão, desde o início do que eu falei eu já estava dizendo que ele tinha morrido. (M7)

$\mathrm{Na}$ tentativa de contornar a comunicação da morte, esse médico informa todos os procedimentos realizados no paciente no tempo verbal passado. O intuito do médico com essa comunicação no passado é para que os familiares se deem conta do desfecho final sem que ele precise de fato comunicar. No entanto, o que se percebeu no relato, foi o fato de que os familiares não possuem essa compreensão que o médico gostaria que tivessem. Isto porque há de se considerar que numa situação como essa, geralmente, a esperança sempre existe e, mesmo com a comunicação no passado, os familiares esperam que o desfecho final seja positivo. Ao não estar preparado para lidar com as emoções que possam emergir, o que o médico tenta evitar é ser explícito. Dessa forma, ao fazer afirmações indefinidas, o médico sempre deixa a possibilidade de o familiar acreditar naquilo que é menos angustiante, podendo levar a falhas na comunicação. Assim, pode-se afirmar que os entrevistados apresentaram dificuldade e desconforto com a comunicação de má notícia. Em suma, o que se evidenciou é que, se por um lado existe uma preocupação de procurar elementos para melhorar sua comunicação com o familiar, por outro não existe uma técnica médica para lidar com essas situações, e sim esquemas individuais, baseados nas próprias experiências pessoais e no senso comum.

\section{Entre a Aproximação e o Afastamento na Comunicação de Más Notícias}

Ainda que não exista uma padronização na forma de dar as más noticias aos familiares, foram observados dois meios distintos. Um representa uma tentativa de se aproximar do familiar, saber da sua preocupação para organizar a comunicação. O outro pode ser visto como a necessidade de apaziguamento das emoções. Entre as que representam uma tentativa de aproximação destaca-se:

O que nós temos para falar de novo? (M3)

Eu gosto de perguntar sempre, assim, o que que o paciente está esperando. Sempre eu gosto de fazer uma pergunta e ver o que eles estão sentindo, dependendo da ocasião, se eu tenho oportunidade ou não, e aí, já ir meio que preparando a familia. (M10)

Até onde tu sabe? (M6)

Pensa-se que esse início, com uma pergunta, seria uma maneira de o médico ir formulando a sua comunicação de modo que venha ao encontro das preocupações do familiar. Assim, aquilo que será informado terá mais probabilidades de ser compreendido. Porém, há comunicações estritamente objetivas, que acabam causando um afastamento na relação, como se existisse um temor de desencadear sentimentos e emoções nos familiares, as quais o médico não saberia manejar. Assim, alguns médicos iniciam a conversa já informando dados sobre a evolução do quadro do paciente, geralmente com uso de jargões. Apresentando uma forma mais objetiva e mais rápida de comunicar:

O que tem de novo: não está dializando. O que tem de igual é que o quadro continua estável. (M6)

Cresceu bactéria na ultima cultura de secreção traquial. (M3) Acho que passaram para a senhora que ela já está a quatro dias sem remédio e ela não tem reação. (M8)

Esse mal-estar frente a possíveis situações angustiantes originadas pela comunicação das más notícias pode ser evidenciado em expressões utilizadas momentos antes da comunicação de más notícias aos familiares de pacientes. Era frequente a expressão de frases jocosas como:

Vamos para a dor? (M7)

Vamos dar a cara a tapa? (M11)

Ainda, se compreende que, em situações geradoras de estresse, como uma grave piora no quadro do paciente, alguns médicos realizam a sua comunicação sem que de fato comuniquem algo. Por exemplo, ao ser questionado se o quadro do paciente é grave ou estável, o médico não dá uma definição do quadro do mesmo, limitando-se a uma resposta ambivalente, como se percebeu da fala:

Um paciente da UTI tem que esperar passar um tempo, pois pode estar evoluindo bem e de repente piorar. (M8)

É importante colocar que além da fala pausada, nessas situações, o tom de voz se apresenta muito mais baixo. Diferente de quando se trata de notícias boas, em que o tom de voz é mais alto do que o trivial e ainda se faz uso de brincadeiras ou piadas durante a comunicação. Como se observou na fala:

Está em alta [se referindo ao paciente], já está rindo até, está mais bonito que o senhor. (M9)

Ah, essa que era a melhor notícia eu não vou poder dar [risos]. (M2) [Os familiares não compareceram para falar com o médico]. 
$\mathrm{O}$ riso e as piadas em meio à comunicação, quando se trata de boas notícias, demonstram o quanto é difícil para o médico quando deve comunicar o oposto: uma má notícia. Assim, esse comportamento no qual se procura evitar os sentimentos, mostra claramente o sofrimento desse profissional obrigado a lidar com a dor de outro ser humano; sem ter ferramentas apropriadas que o ajudem a aliviar o sofrimento do familiar e também a se proteger da angústia que essa situação de sofrimento provoca nele mesmo. Parece que o médico encontra-se em uma corda bamba na sua profissão, podendo a qualquer momento entrar em contato com sentimentos de euforia ou de tristeza. Outro contraponto é referido por Cano (2008), que considerou o humor como forma de evitar o contato com as emoções. Assim, trabalhar em clima de brincadeira seria uma forma de externalizar as emoções de outro modo, o que não deixa de ser uma forma de negação como meio para enfrentar as vicissitudes do cotidiano médico.

\section{Uma Angústia Compartilhada: Más Notícias para quem?}

A comunicação de más notícias é uma atividade corriqueira na profissão médica, como já visto, no entanto, aparece como uma tarefa que o médico gostaria de evitar, como se apresenta no relato:

E no dia que eu fui lá para contar, na casa dele, de manhã, acho que eu tomei uns dez litros de chá, de nervosa que eu estava. E as enfermeiras só riam: "O que é que tu tem?” Nada. Dai chegou na hora e eu disse: "Não quero ir. Não vou fazer a visita hoje, vamos outro dia". Eu fugi, mas dai fui, falei, os filhos falaram. (M6)

Nota-se igualmente nos relatos que é preciso haver uma preparação prévia do médico para que ele possa comunicar uma má notícia. Segundo Seabra e Costa (2015), os médicos possuem dificuldades em realizar a comunicação de más notícias, indicando ansiedade, nervosismo e desconforto em realizar essa tarefa; e alívio ao terminá-la, dependendo da reação do paciente. Esses sentimentos podem justificar o fato de alguns profissionais se prepararem anteriormente e reservarem um tempo especial para realizar a comunicação. Pode-se salientar que essa preparação está relacionada tanto a uma questão mais técnica de como comunicar, quanto aos sentimentos que emergem frente a essa tarefa. Percebe-se, então, que o fato de a comunicação, e aqui, principalmente, da má notícia, não é apenas a passagem de informação. Se há a necessidade de se preparar é porque essa tarefa é difícil e envolve sentimentos, tanto do lado de quem emite a notícia, no caso o médico, quanto de quem a recebe. A preparação que o médico faz antes de comunicar leva a pensar em uma angústia frente à comunicação de más notícias; portanto, ele não se encontra preparado para comunicar. Logo, a comunicação de más notícias é percebida pelos médicos como uma obrigação desagradável; um mal necessário. Pode-se questionar: Como o médico se prepara? Quais são as ferramentas, as teorias das quais ele lança mão para fazer esse preparo? Do que transparece das falas, a preparação dá-se muito mais por meio da intuição. Corroborando com essa ideia, Grinberg (2010) destacou que, embora possa se fazer valer da intuição na comunicação em saúde, deveriam ser desenvolvidos programas de treinamento com o objetivo de se alcançar um maior grau de clareza e exatidão na comunicação.

Deve-se inferir então que, para o médico se utilizar de sua intuição, seria de suma importância que este tivesse além de um preparo relacionado a uma base científica, a possibilidade de refletir sobre os seus sentimentos frente à doença e à morte. Isto porque, como abordou Quintana (2009), o médico pode falar racionalmente da morte, ele não pode é senti-la, permitir que ela toque seus sentimentos, refletindo no despreparo dos profissionais da saúde em lidar com essas situações. Um adequado preparo teórico e emocional permitiria não apenas uma melhor comunicação com o paciente como, também, uma diminuição do grau de ansiedade do profissional, como a apresentada no seguinte depoimento:

Eu fiquei acho que dois dias pensando como é que eu ia dizer. [...] Quando veio o diagnóstico eu fiquei dois dias pensando, até que eu liguei para ela, pedi para ela vir ao hospital, que eu tinha que conversar com ela. [...] Mas eu fiquei, assim, quando eu peguei o resultado e fiquei pensando: “meu Deus, como é que eu vou falar". Na hora quem falou foi ela, depois eu fiquei meio ruizinha, mas dai eu já vi ela depois na terapia e estava evoluindo bem e ai eu já me senti melhor [...] Lembro o nome, a idade e o sangue até, se tu quiseres. (M6)

$\mathrm{O}$ depoimento do entrevistado revela angústia frente à necessidade de comunicar o resultado negativo das análises feitas pela paciente no qual constata a existência de câncer. Essa angústia reflete certa paralização do entrevistado, que deixa passar um tempo (dois dias) para comunicar isso à paciente. Inclusive, essa angústia pode ter resultado em que a má noticia não foi de fato comunicada, mas, a própria paciente teve que afirmar isso. Igualmente, o médico se pergunta: "meu Deus, como é que vou falar?". A fala demonstra o sofrimento, a angústia e o despreparo frente à comunicação de más notícias, capaz de gerar um impacto emocional muito forte nos profissionais, sendo que essa situação fica registrada na lembrança deles. Isso ressalta que o preparo do médico não deve ser puramente teórico, ele deve ser igualmente produto de reflexão, pois, se o médico não refletiu e trabalhou suas dificuldades frente à morte e ao morrer, certamente terá dificuldades na comunicação, ainda que possua uma fundamentação teórica para isso.

Esse impacto emocional também se apresenta no próprio fato de ter que comunicar uma má notícia, pois a partir dessa comunicação deve-se pensar na pessoa que a ouviu, seja paciente, familiar ou alguém que possua algum laço afetivo com o paciente. Além disso, os sentimentos e anseios presentes nas duas faces da relação podem prejudicar o desenvolvimento de uma boa comunicação (Jucá et al., 2010). Após a comunicação, o que fica é a reação de quem a recebeu e é com isso que o médico precisa lidar. Assim, é possível se pensar, também, no quanto a reação de quem recebe a notícia pode gerar angústia no médico que, muitas vezes, comunica e se retira, não dando um suporte/acolhimento ao paciente/ familiar, como se percebe na fala: 
Como é que eles vão metabolizar isto, eu não sei. A gente não acompanha depois, né. Passa as informações e não fica mais. (M9)

Os médicos não conseguem ficar assistindo ao sofrimento do outro e não sabem como agir nessa situação, pois, mesmo com uma comunicação considerada adequada pelo médico, a comunicação de más notícias é sempre difícil, porque ela vai trazer uma realidade que muda, de forma negativa, a vida de quem está recebendo a comunicação. Talvez seja justamente esse ponto que gera angústia para os médicos. Eles vão comunicar o que inevitavelmente vai gerar sofrimento no outro e vão assistir a esse sofrimento. Assim, infere-se que a comunicação de más notícias gera momentos perturbadores, tanto na pessoa que emite quanto na que recebe a notícia. Por esse motivo, a comunicação de más notícias é considerada pelos profissionais de saúde uma tarefa difícil de enfrentar, não apenas pelo receio das reações emocionais que surgem em quem recebe a notícia - paciente e/ou familiares, mas, igualmente, pela dificuldade de conduzir essa situação (Pereira, 2005). Um entrevistado verbalizou essa situação de angústia frente ao sofrimento do outro de forma muito clara:

Mas, não vou te enganar, que do [nome do paciente] eu fujo. Eu não consigo, assim, quando eu vejo, que ele está chorando, que está precisando de alguma coisa, eu chego ali, converso, tento resolver o problema dele, mas, eu tento resolver, e no momento que eu vejo que ele ficou bem, que ele pode querer conversar sobre outras coisas, que ele não vai caminhar, que ele não vai, ... eu saio fora, eu não digo que isso é certo, eu sei que isso é errado, ... mas, eu, infelizmente, eu não consigo. (M1)

É importante a fala desse médico, pois ele explicita claramente o sentimento de angústia e impotência que possui frente ao sofrimento do paciente. Mesmo tendo certeza de que faz errado ao fugir da situação, ele relata que não consegue ficar para ouvi-lo. De fato, há um custo emocional para esse profissional nas duas situações: quando ele fica para ouvir o paciente, o que lhe gera muita angústia; ou, quando ele o abandona, sabendo que está fazendo algo errado e se culpabilizando por isso. Nesse sentido, fica implícito um pedido de que alguém tome esse papel que não seja ele. Outros médicos relataram sobre a dificuldade desse caso em específico, logo, esse papel seria de "ninguém", ou de profissionais que hierarquicamente seriam obrigados a recebê-lo.

Ressalta-se que a identificação com os pacientes seria fonte do aumento da angústia sentida pelos médicos.

Ai, no caso específico do [nome do paciente], porque, assim, ..., eu me imagino me dizendo que eu não vá mais caminhar. Bah, isto para mim é muito dificil. Eu acredito que para ele, também, tenha sido a mesma coisa, ele vai ter momento da negação, da raiva, e depois vai aceitar. (M4)

Nota-se que quando há um processo de identificação, a tendência do médico é sofrer mais com a situação. Ainda, o choro e o desespero do familiar são a expressão de sua angústia em face da impotência para solucionar a doença ou a morte.

Eu não quero ver alguém da família berrando na minha frente, chorando. Parece que tu não fez nada, né. Tu fez, tu sabe que tu fez tudo o que tu podia fazer. Tu ficou 50 minutos tentando reanimar um paciente e não conseguiu. E aí a família pergunta se eu fiz tudo o que tinha de fazer. Não, eu fiz tudo o que tinha para fazer. Parece traumático, para mim também é. (M6)

A comunicação de más notícias representa o sentimento de fracasso do médico. Dessa forma, ela é difícil tanto para os familiares quanto para o próprio médico, que se defronta com a perda da onipotência. Diferente de quando a comunicação se refere a notícias boas, na qual a sensação é inversa, já que nesta se confirma a onipotência, o prazer do médico ao salvar uma vida. É importante considerar que membros da mesma família terão reações diferentes em relação à mesma notícia. Esses comportamentos individuais e psicossociais não podem ser modificados pelo médico. Mas, ao saber dessas diferenças e buscar entender o funcionamento de cada família, poderá haver uma comunicação mais eficaz e uma melhor formação de vínculo na relação (Traiber \& Lago, 2012).

\section{Considerações Finais}

Por um lado, têm-se profissionais da saúde que não se sentem preparados para comunicar más notícias e por isso sofrem ao realizá-la, por outro, têm-se a necessidade de comunicá-las como atividade quase que diária da profissão. Pode-se considerar que o impasse começa desde a formação médica, que mesmo que esteja num processo de transformação, ainda encontra-se voltada aos ditames da ciência positivista, no qual o subjetivo se encontra em segundo plano frente a tantos ensinamentos sobre o orgânico. Com efeito, prevalece uma formação que desenvolve uma barreira para que sentimentos e emoções não surjam na prática clínica. Assim, sobra ao estudante aprender pela prática e observação daqueles que também aprenderam dessa forma.

A relação médico-paciente/familiar acontece pela interação e esta pela comunicação, seja ela verbal ou nãoverbal. Para tanto, o médico deve compreender que sua palavra possui tanto valor quanto seu comportamento. E que à sua frente há alguém fragilizado pela doença, pela incerteza do desconhecido. Neste contexto que se encontra o maior problema na relação, a fragilidade do outro mostra ao médico a sua própria fragilidade, a finitude do paciente faz o médico pensar em sua própria finitude. E isso traz sofrimento. Para evitá-lo, para aliviar angústias, reduzir tensões e amenizar sentimentos, mecanismos de defesa são ativados, muitas vezes não permitindo um manejo adequado das questões emocionais.

Ainda, deve ser considerado que a comunicação de más notícias traz à tona sentimentos para aqueles que a recebem. O médico precisa acolher essas emoções, contudo, não possui um aparato teórico ou emocional que lhe alicerce. Então, a fuga acontece atrás de protocolos que expliquem os passos indispensáveis para se lidar com essas reações. Mas, não há protocolo que dê conta dessa profusão afetiva, e só resta ao médico sair da situação o mais rápido possível. A partir das evidências, torna-se então necessário resgatar a importância da reflexão sobre a relação médico-familiar como prática diária tão importante quantos outros ensinamentos da medicina. Prática que envolva tanto um aparato teórico, que instrumentalize e auxilie na resolução de problemas, como 
um aparato que lide com sentimentos e emoções dos futuros médicos. Ainda, corrobora-se o fato de que os médicos não precisam agir sozinhos. Há uma equipe interdisciplinar que pode auxiliá-los nessa árdua tarefa; trocando experiências, falando sobre os sentimentos e participando ativamente em prol dos familiares. Evidencia-se, também, a necessidade de cursos de atualização para que os médicos já formados possam realizar uma reflexão acerca dos seus sentimentos, no intuito de uma assistência integral ao paciente.

\section{Referências}

Almeida, M. D. D., \& Santos, A. P. A. L. (2013). Câncer infantil: O médico diante de notícias difíceis: uma contribuição da psicanálise. Mudanças, 21(1), 49-54. doi: http://dx.doi. org/10.15603/2176-1019/mud.v21n1p49-54

Araújo, M. M. T. de, \& Silva, M. J. P. da (2012). O conhecimento de estratégias de comunicação no atendimento à dimensão emocional em cuidados paliativos. Texto Contexto Enfermagem, 21(1), 121-9. doi: http://dx.doi.org/10.1590/ S0104-07072012000100014

Bardin, L. (2008). Análise de Conteúdo. Lisboa: Ed. 70.

Borges, M. D. S., Freitas, G., \& Gurgel, W. (2012). A comunicação da má notícia na visão dos profissionais de saúde. Tempus Actas de Saúde Coletiva, 6(3), 113-126. doi: http://dx.doi. org/10.18569/tempus.v6i3.1159

Borges, R., \& D’Oliveira, A. F. P. L. (2011). A visita médica domiciliar como espaço para interação e comunicação em Florianópolis, SC. Interface - Comunicação, Saúde, Educação, 15(37), 461-472. Retrieved from: http://www.scielo.br/pdf/ icse/v15n37/a11v15n37.pdf

Brasil. (2012). Conselho Nacional de Saúde. Resolução $N^{\circ}$ 466/2012. Sobre Pesquisa Envolvendo Seres Humanos. Diário Oficial [da] República Federativa do Brasil. Brasília, DF. Retrieved from: http://bvsms.saude.gov.br/bvs/saudelegis/ cns/2013/res0466 12_12 2012.html

Cano, D. S. (2008). O profissional que está no fio-entre a vida e a morte: Vivências, Concepções e Estratégias de Enfrentamento Psicológico de médicos oncologistas (Unpublished master's thesis). Universidade Federal de Santa Catarina, Florianópolis.

Castro, E. K. D., \& Barreto, S. M. (2015). Oncology medical criteria for psychological referral in palliative care. Psicologia: Ciencia e Profissão, 35(1), 69-82. doi: http://dx.doi.org/10.1590/19823703000202013

Fornaziero, C. C., Gordan, P. A., \& Garanhani, M. L. (2011). O Processo de Ensino e Aprendizagem do Raciocínio Clínico pelos Estudantes de Medicina da Universidade Estadual de Londrina. Revista Brasileira de Educação Médica, 35(2), 246-253. Retrieved from: https://www.researchgate.net/profile/ Mara_Garanhani/publication/262613910_The_teaching_and learning_process_in_clinical_reasoning_among_medical_ students_at_the_State_University_in_Londrina_Paran/ links/53f1f3060 $\bar{c} 272810 \mathrm{e} 4 \mathrm{c} 793 \mathrm{e} . \mathrm{pdf}$

Gil, A. C. (2010). Como elaborar um projeto de pesquisa (5a ed.). São Paulo: Atlas.

Grinberg, M. (2010). Comunicação em oncologia e bioética [Editorial]. Revista da Associação Médica Brasileira, 56(4), 375-393. doi: http://dx.doi.org/10.1590/S010442302010000400001
Jucá, N. B. H., Gomes, A. M. A., Mendes, L. S., Gomes, D. M., Martins, B. V. L., Silva, C. M. G. C., ... Caprara, A. (2010). A comunicação do diagnóstico "sombrio" na relação médico-paciente entre estudantes de medicina: Uma experiência de dramatização na educação médica. Revista Brasileira de Educação Médica, 34(1), 57-64. Retrieved from: https://www.researchgate.net/profile/ Kathiane_Augusto/publication/262617106_Communicating an_unfavorable_diagnosis_during_the_physician-patient_ relationship_a_role-playing_experiment_with_medical_ students/links/0a85e53a30edfac1d9000000.pdf

Lino, C. A., Augusto, K. L., Oliveira, R. A. S., Feitosa, L. B., \& Caprara, A. (2011). Uso do Protocolo Spikes no Ensino de Habilidades em Transmissão de Más Notícias. Revista Brasileira de Educação Médica, 35(1), 52-57. Retrieved from: file://C:/Users/wi7pc/Downloads/p.52-57_pesquisa_ uso + do + protocolo $\% 20(1) \cdot p d f$

Lottenberg, C. L. (2010). Prefácio. In Instituto Nacional de Câncer e Sociedade Beneficente Israelita Brasileira Albert Einstein. Ministério da Saúde (MS), Comunicação de notícias difíceis: compartilhando desafios na atenção à saúde. Rio de Janeiro: INCA. Retrieved from http://www1.inca.gov.br/inca/Arquivos/ comunicacao/comunicacao_noticias_dificeis.pdf

Lucchese, F. A., \& Ledur, P. F. (2008). Comunicação médicopaciente: Um acordo de cooperação. Porto Alegre, RS: AGE.

Minayo, M. C. de S. (2010). O desafio do conhecimento: pesquisa qualitativa em saúde. São Paulo: Hucitec.

Moritz, R. D., Lago, P. M., Souza, R. P., Silva, N. B., Meneses, F. A., Othero, J. C. B., ... Azeredo, N. (2008). Terminalidade e cuidados paliativos na unidade de terapia intensiva. Revista Brasileira de Terapia Intensiva, 20(4), 422-428. Retrieved from: http://hdl.handle.net/10183/22970

Penello, L., \& Magalhães, P. (2010). Comunicação de Más Notícias: Uma Questão se Apresenta. In Instituto Nacional de Câncer e Sociedade Beneficente Israelita Brasileira Albert Einstein. Ministério da Saúde (MS), Comunicação de notícias dificeis: compartilhando desafios na atenção à saúde. Rio de Janeiro: INCA. (pp. 23-35). Retrieved from: http://www1.inca.gov.br/ inca/Arquivos/comunicacao/comunicacao_noticias_dificeis. pdf

Pereira, M. A. G. (2005). Má notícia em saúde: Um olhar sobre as representações dos profissionais de saúde e cidadãos. Texto Contexto Enfermagem, 14(1), 33-37.

Quintana, A. M. (2009). Morte e formação médica: É possível a humanização? In: S. S. Franklin (ed.), A arte de morrer. Visões Plurais. (v. 2, pp. 37-48). Bragança Paulista, SP: Comenius.

Rodrigues, L. A., Moraes, E. L., Betoschi, J. R., \& Amaral, C. P. (2015). Como a dor e o sofrimento do paciente oncológico afetam o médico no processo de tratamento. Revista CuidArte, $9(1), 58-70$.

Rodriguez, M. I. F. (2014). Despedida silenciada: Equipe médica, família, paciente-cúmplices da conspiração do silêncio. Psicologia Revista. Revista da Faculdade de Ciências Humanas e da Saúde, 23(2), 261-272.

Rossi-Barbosa, L. A. R., Lima, C. C., Queiroz, I. N., Fróes, S. S., \& Caldeira, A. P. (2010). A percepção de pacientes sobre a comunicação não verbal na assistência médica. Revista Brasileira de Educação Médica, 34(3), 363-370. 
Santos, L. F., Oliveira, L. M. D. A., Veronez, M. K. A., \& Nogueira, A. L. G. (2015). Quando a comunicação é nociva no encontro entre profissional e família da criança hospitalizada. Enfermería Global, 14(1), 192-203.

Seabra, F. L., \& Costa, M. J. (2015). Comunicação de más notícias pelos médicos no primeiro ano de internato: Um estudo exploratório. FEM. Revista de la Fundación Educación Médica, 18(6), 387-395.

Traiber, C., \& Lago, P. M. (2012). Comunicação de más notícias em pediatria. Boletim Científico de Pediatria, 1(1). Retirado de http://www.sprs.com.br/sprs2013/bancoimg/13121015203 0bcped_12_01_02.pdf
Turato, E. R. (2013). Tratado da metodologia da pesquisa clínico qualitativa. (6a ed.) Petrópolis, RJ: Vozes.

Recebido em 12.06.2013

Primeira decisão editorial em 28.03.2016

Versão final em 13.08.2016

Aceito em 13.08.2016 